\title{
Matemática Financeira: uma proposta de abordagem para o Ensino Médio por meio do tesouro direto
}

\author{
Luiz Eduardo da Silva Gomes (D)
}

\begin{abstract}
Resumo
Neste artigo propomos uma abordagem de ensino de Matemática Financeira para o Ensino Médio, mediante apresentação de atividades que relacionam problemas envolvendo simulações de investimentos no tesouro direto, ver <https://www.tesourodireto.com.br/simulador/>, e alguns conceitos matemáticos aplicados a esse investimento. Essa abordagem visa aproximar tais conceitos à vida cotidiana dos discentes e, além disso, atende as competências e habilidades da área de Matemática e suas tecnologias que estão inseridas na Base Nacional Comum Curricular, quando estabeleceu que "no Ensino Médio o foco é a construção de uma visão integrada da Matemática, aplicada à realidade, em diferentes contextos", ver [9, p.528]. Concluímos esse artigo apresentando as atividades, e suas respectivas resoluções, usando o tesouro direto.
\end{abstract}

Palavras-chave: Matemática Financeira; Proposta didática; Tesouro direto; Ensino Médio; BNCC.

\begin{abstract}
In this article we propose an approach to teaching Financial Mathematics for High School, by presenting activities that relate problems involving investment simulations in the direct treasury, see <https://www.tesourodireto.com.br/simulador/>, and some mathematical concepts applied to this investment. This approach aims to bring such concepts closer to the students' daily lives and, in addition, meets the competencies and skills of the area of Mathematics and its technologies that are inserted in the Common National Curricular Base, when it established that "in High School the focus is on the construction of an integrated view of Mathematics, applied to reality, in different contexts", see [9, p.528]. We conclude this article by presenting the activities, and their respective resolutions, using the direct treasure.
\end{abstract}

Keywords: Financial math; Didactic proposal; Direct treasure; High school; BNCC.

\section{Introdução}

A Matemática, reconhecidamente, possui grande importância e aplicabilidade em diversas áreas do conhecimento. Todavia, essa importância e aplicabilidade precisam ser claras também para os estudantes. Qual professor do ensino básico nunca ouviu perguntas do tipo: "Onde vou utilizar esse assunto em minha vida?" ou "Por que precisamos estudar esse assunto?". De fato, não há sentido nem ânimo em se dedicar horas e horas para aprender conceitos que não parecem ter muita utilidade. Fundamentado em nossa experiência em sala de aula, entendemos que quando tal 
conteúdo é apresentado evidenciando sua aplicabilidade no cotidiano dos alunos, mais engajados eles estarão para o aprendizado.

Dessa forma, visando dar aos alunos uma maior relevância à área de Matemática, é necessário debruçarmo-nos sobre como abordar determinados conhecimentos de tal forma que o conteúdo faça sentido para eles, desperte o interesse em aprendê-lo, e provoque o reconhecimento e a importância do tema tratado. Isso, certamente, acarretaria o desenvolvimento das competências e habilidades específicas de Matemática na etapa do Ensino Médio descritas na Base Nacional Comum Curricular (BNCC), ver [9]. É importante destacar que a BNCC é um documento que define as aprendizagens essenciais que deverão ser trabalhadas na Educação Básica pelas escolas brasileiras, sejam elas públicas ou privadas. Ela estabelece conhecimentos, competências e habilidades que se espera que todos os estudantes desenvolvam ao longo da escolaridade básica.

\section{Ao longo da Educação Básica, as aprendizagens essenciais definidas na BNCC devem concorrer para assegurar aos estudantes o desenvolvimento de dez competências gerais, que consubstanciam, no âmbito pedagógico, os direitos de aprendizagem e desenvolvimento. [9, p.8].}

A própria BNCC traz a definição de competência e habilidade:

Na BNCC, competência é definida como a mobilização de conhecimentos (conceitos e procedimentos), habilidades (práticas, cognitivas e socioemocionais), atitudes e valores para resolver demandas complexas da vida cotidiana, do pleno exercício da cidadania e do mundo do trabalho. [9, p.8].

Ainda sobre o termo competências e habilidades, a Resolução № 4, de 17 de dezembro de 2018, que instituiu a Base Nacional Comum Curricular na etapa do Ensino Médio (BNCC-EM) como etapa final da Educação Básica, define esse termo, em seu parágrafo único do art $3^{\circ}$, da seguinte maneira:

Parágrafo único. Para os efeitos desta Resolução, com fundamento no caput do art. 35-A e no $\S 1^{o}$ do art. 36 da LDB, a expressão "competências e habilidades" deve ser considerada como equivalente à expressão "direitos e objetivos de aprendizagem" presente na Lei do Plano Nacional de Educação (PNE). [10].

Além disso, é importante que o professor busque e utilize vários recursos e instrumentos que venham ajudá-lo a fortalecer o ensino e, especialmente, a aprendizagem da Matemática, como por exemplo, os recursos tecnológicos.

Convém ressaltar que o uso de tecnologias nas aulas de Matemática tem se consolidado com o passar dos anos, reflexo das aceleradas mudanças e oportunidades de utilização de recursos bem conhecidos como o GeoGebra, planilhas eletrônicas, aplicativos de smartphone e simulações. Essa utilização foi objeto de estudo em publicações recentes, ver por exemplo, [13], [15] e [22], que ressalta, dentre outras conclusões, a eficácia da utilização de tais recursos na melhoria de aprendizagem dos estudantes.

Um tema que tem chamado muito a atenção e tem sido frequentemente apresentado em vídeos veiculados na internet, sites, revistas e mídias sociais são os investimentos. O homem, desde cedo, 
em sua infância, lida com o dinheiro e deverá ser capaz de administrá-lo em toda sua trajetória de vida. Saber, portanto, como administrar e investir o dinheiro é essencial para uma vida financeira de maior qualidade.

O objetivo desse artigo é propor uma abordagem de ensino de Matemática Financeira para o Ensino Médio, mediante apresentação de atividades, que relacionam problemas envolvendo simulações de investimentos no tesouro direto e alguns conceitos matemáticos aplicados a esse investimento. Nessa abordagem usamos como recurso o site do tesouro direto, ver <https://www.tesourodireto. com.br/simulador/>, e uma calculadora científica.

\section{Alguns conceitos relacionados à economia}

Nesta seção, tendo em vista o potencial do tema e suas relações com as competências e habilidades previstas na BNCC, abordaremos alguns conceitos que permeiam este trabalho com um caráter de revisão.

\subsection{Inflação}

Um conceito muito importante para a Economia é a inflação. Basicamente, o processo inflacionário de uma economia pode ser entendido pelo aumento generalizado dos preços de vários bens e serviços importantes no dia a dia das pessoas, ver [19, p.61]. Por exemplo, se a inflação em determinado mês for de $0,6 \%$, isso significa que o aumento médio dos preços desses bens e serviços no período também foi de 0,6\%. Dessa forma, a inflação implica a diminuição do poder de compra da moeda, ver [6]. Para saber a respeito do conceito de moeda, ver [16, p.105-118]. Quando ocorre a diminuição dos preços de bens e serviços ocorre o fenômeno chamado de deflação, ver [19, p.61].

No Brasil o indicador oficial de inflação é o Índice de Preços para o Consumidor Amplo (IPCA), ver [8]. Ele é calculado mensalmente pelo Instituto Brasileiro de Geografia e Estatística (IBGE) em algumas regiões metropolitanas do país, ver [8]. E apesar de não ser calculado em todo o país, o IPCA é de abrangência nacional, isto é, ele serve como indicador do aumento médio dos preços de determinados bens e serviços de todos os estados do país. A taxa de inflação é a variação do custo da cesta de produtos e serviços, ou cesta do IPCA, durante determinado período. Essa cesta inclui os itens: transporte, vestuário, alimentação e bebidas, habitação, educação, saúde e cuidados pessoais, comunicação e outras despesas pessoais, ver [6]. O Brasil possui uma meta anual de inflação para dar segurança para a economia, ver [5]. Essa é uma forma de garantir que a economia brasileira continue em crescimento e os preços, controlados. A inflação torna-se prejudicial para a economia de um país quando ela sai do controle e atinge altos níveis, fenômeno chamado de hiperinflação.

\subsection{Taxa Selic}

A taxa Selic, Sistema Especial de Liquidação e Custódia, é a taxa básica de juros da economia usada pelo Banco Central, dentre outras coisas, para controlar a inflação. Ela também é usada como referência em operações e empréstimos realizados entre os bancos, e também afeta os rendimentos de investimentos de renda fixa, dentre eles os títulos públicos e a caderneta de poupança.

Ela é definida a cada 45 dias pelo Comitê de Política Monetária (Copom), ver [3], ligado ao Banco Central, que se baseia em outros indicadores financeiros do país. Atualmente, desde 06 de agosto 
de 2020, a Selic alcançou a marca de 2\% a.a., ver [1]. Assim, exibimos na Tabela 1 os valores da taxa Selic durante o período entre setembro de 2017 a outubro de 2020, ver [4].

Tabela 1: Taxa Selic do período 09/2017 a 10/2020

\begin{tabular}{ccc} 
Vigência & $\begin{array}{c}\text { Número de reunióes do Copom } \\
\text { no periodo de vigência }\end{array}$ & $\begin{array}{c}\text { Taxa Selic } \\
\text { (ao ano) }\end{array}$ \\
\hline $06 / 08 / 2020-28 / 10 / 2020$ & 2 & $2 \%$ \\
\hline $18 / 06 / 2019-05 / 08 / 2020$ & 1 & $2,25 \%$ \\
\hline $07 / 05 / 2020-17 / 06 / 2020$ & 1 & $3 \%$ \\
\hline $19 / 03 / 2029-06 / 05 / 2020$ & 1 & $3,75 \%$ \\
\hline $06 / 02 / 2019-18 / 03 / 2020$ & 1 & $4,25 \%$ \\
\hline $12 / 12 / 2019-05 / 02 / 2020$ & 1 & $4,50 \%$ \\
\hline $31 / 10 / 2019-11 / 12 / 2019$ & 1 & $5 \%$ \\
\hline $19 / 09 / 2019-30 / 10 / 2019$ & 1 & $5,50 \%$ \\
\hline $01 / 08 / 2019-18 / 09 / 2019$ & 1 & $6 \%$ \\
\hline $22 / 03 / 2018-31 / 07 / 2019$ & 11 & $6,50 \%$ \\
\hline $08 / 02 / 2018-21 / 03 / 2018$ & 1 & $6,75 \%$ \\
\hline $07 / 12 / 2017-07 / 02 / 2018$ & 1 & $7 \%$ \\
\hline $26 / 10 / 2017-06 / 12 / 2017$ & 1 & $7,50 \%$ \\
\hline $07 / 09 / 2017-25 / 10 / 2017$ & 1 & $8,25 \%$ \\
\hline
\end{tabular}

Fonte: [4]

\section{Investimenos financeiros}

Um investimento financeiro é, basicamente, uma aplicação de um valor em dinheiro em que há uma expectativa de rendimento futuro. Isso ocorre por conta do efeito dos juros compostos sobre as aplicações financeiras, que faz com que o dinheiro aplicado tenha um crescimento nominal com o tempo.

Não é preciso ser um especialista em finanças para começar a investir. No entanto, para evitar prejuízos e ter bons rendimentos é importante conhecer bem o tipo de investimento desejado. Nesta seção falaremos sobre alguns tipos de investimentos do mercado financeiro, dentre eles, os títulos públicos do tesouro direto.

\subsection{Caderneta de poupança}

A caderneta de poupança é considerada a modalidade de aplicação financeira mais popular do mercado. Seus principais atrativos encontram-se na liquidez imediata (o aplicador pode sacar seu saldo a qualquer momento), na isenção do Imposto sobre Operações Financeiras (IOF), na isenção do Imposto de Renda (IR) e também na cobertura do Fundo Garantidor de Crédito (FGC), o qual protege o investidor em aplicações de até $\mathrm{R} \$ 250.000,00$ por Cadastro de Pessoa Física (CPF), por 
instituição, respeitando o limite de quatro instituições. É importante salientar que esses atrativos não são exclusivos da poupança, podendo aparecer em outros investimentos.

Um ponto negativo da poupança é o baixo rendimento, podendo até perder dinheiro (de forma mais técnica, perder o poder de compra), caso em que a inflação é maior do que o rendimento oferecido pela poupança. Outro ponto negativo é que os juros da caderneta de poupança são pagos mensalmente no dia do aniversário, ver [7]. O aniversário da poupança pode ser o dia de abertura da conta ou a data em que foi feito o depósito. Como o rendimento da poupança é mensal, retirando-se o dinheiro da conta antes da data de aniversário, perde-se todo o rendimento do período. Por exemplo, depositando-se $\mathrm{R} \$ 75.000,00$ na poupança e resgatando todo esse valor antes de completar os 30 dias, não haverá rendimento nesse período.

Atualmente os juros pagos pela aplicação na caderneta de poupança depende do valor da taxa Selic, com acréscimo da Taxa Referencial (TR), que é uma taxa obtida a partir das médias das taxas de juros utilizadas nos certificados de depósito interbancários ofertados por bancos comerciais, ver [7] e $[2]$.

São dois os cenários possíveis de rentabilidade:

1) Se a taxa Selic for superior a 8,5\%, então a remuneração da poupança será de $0,5 \%$ ao mês mais a TR;

2) Caso a Selic seja igual ou menor do que 8,5\% ao ano, o rendimento da poupança será de $70 \%$ da Selic mais a TR.

Visto que atualmente a taxa Selic está em 2\% a.a., o rendimento da poupança segue a regra do segundo cenário. Portanto, o rendimento atual da poupança é dado por 0,70 x 2\% + TR. Como a taxa referencial está em 0\%, o rendimento atual (nov. 2020) da caderneta de poupança é de $1,4 \%$ a.a.

\subsection{Títulos públicos}

Os títulos públicos são ativos emitidos pelo governo federal com objetivo de financiar a dívida pública e as atividades do governo tais como educação, saúde, moradia, transporte, infraestrutura, entre outros, permitindo que investidores emprestem dinheiro para o governo visando uma rentabilidade futura. É considerado o investimento de menor risco de uma economia, pois é garantido pelo Tesouro Nacional, ver [27]. O órgão responsável pela emissão e controle dos títulos, e pela administração da dívida mobiliária federal, é a Secretaria do Tesouro Nacional.

O investidor conta com o serviço tesouro direto por meio do qual é possível comprar diretamente, via site na internet, títulos públicos federais do Tesouro Nacional, ver [21]. Para isso, basta possuir CPF e estar cadastrado em alguma das instituições financeiras habilitadas a operar no tesouro direto, ver [31]. Iremos abordar mais detalhadamente o tesouro direto na seção a seguir.

\subsection{Tesouro direto}

O tesouro direto é um programa do Tesouro Nacional desenvolvido em parceria com a Bolsa de Valores do Brasil (B3), para venda de títulos públicos federais para pessoas físicas, de forma $100 \%$ online, ver [27]. Ele foi lançado no ano 2002 com o objetivo de democratizar o acesso aos títulos 
públicos, ver [27]. Com pouco mais de $\mathrm{R} \$ 30,00$ é possível investir no tesouro direto, ver [27], e não é necessário ser um especialista em investimentos, o que facilita a acessibilidade aos jovens que estão iniciando sua trajetória profissional.

Os investimentos em títulos públicos, por meio do programa tesouro direto, são 100\% garantidos pelo Tesouro Nacional, por isso são considerados os investimentos mais seguros do país, ver [27]. Todas as aplicações, resgates e acompanhamentos podem ser realizados pelo site do tesouro direto ou por meio do aplicativo oficial do tesouro direto. Para quem está começando no mundo dos investimentos e tem experiência, o tesouro direto é uma excelente alternativa de investimento, pois oferece títulos com diferentes tipos de rentabilidade (prefixada, ligada à variação da inflação ou à variação da taxa de juros básica da economia - Selic), diferentes prazos de vencimento e também diferentes fluxos de remuneração, ver [27].

Basicamente, temos os seguintes tipos de tesouro:

a) Tesouro prefixado, no qual o investidor sabe exatamente a rentabilidade e quanto vai receber na data de vencimento do título e é mais interessante para quem pode deixar o seu dinheiro render até o vencimento do investimento. Em caso de resgate antecipado, o Tesouro Nacional garante sua recompra pelo seu valor de mercado na data de resgate;

b) Tesouro Selic, no qual a rentabilidade da aplicação é baseada na taxa Selic (a taxa básica de juros da economia), é indicado para aqueles que querem realizar investimentos de curto prazo em título com rentabilidade diária vinculada à taxa de juros da economia (taxa Selic). Isso significa que se a taxa Selic aumentar, a sua rentabilidade aumenta. E se a taxa Selic diminuir, sua rentabilidade diminui;

c) Tesouro IPCA, no qual a rentabilidade da aplicação é baseada em uma parte fixa (prefixada) e uma parte atrelada à variação da inflação, medida pelo Índice de Preços ao Consumidor Amplo (IPCA). O tesouro IPCA é indicado para aqueles que querem realizar investimentos de longo prazo, pois ele garante um rendimento acima da inflação.

É importante saber que em todos os tipos de tesouro há a cobrança de imposto de renda sobre a rentabilidade, conforme abaixo:

- Aplicações até 180 dias: 22,5\%;

- Aplicações de 181 a 360 dias: 20\%;

- Aplicações de 361 a 720 dias: 17,5\%;

- Aplicações acima de 720 dias: $15 \%$.

Essa cobrança ocorrerá na venda do título, no pagamento de juros semestrais ou em seu vencimento, ver [31]. E caso o investidor faça o resgate em menos de 30 dias de aplicação, haverá também a incidência de IOF sobre os rendimentos. A taxa de cobrança do IOF é regressiva, diminuindo com o tempo que o investimento for mantido e desaparecendo ao completar 30 dias de investimento, ver [25].

Além dos dois impostos citados acima há também a cobrança de uma taxa de custódia, cobrada pela B3, que é o lugar onde são negociados os títulos do tesouro direto. O valor cobrado é utilizado 
para guardar os títulos, aprimorar o sistema do tesouro e demais serviços do programa. A taxa de custódia é de 0,25\% sobre o valor total investido, ver [25]. Ainda há a taxa de administração da instituição financeira, também conhecida como taxa do agente de custódia. A taxa de administração é um valor cobrado pela corretora ou banco para investir no tesouro direto. O percentual da taxa é determinado por cada instituição, podendo ser taxa zero, ver [25]. Dessa forma, para aumentar a competitividade, muitas instituições isentam seus clientes dessa cobrança.

Mostramos na Figura 1 uma tabela retirada do site do tesouro direto, ver [26], com as opções de compra de títulos (referência 09/06/2020):

Figura 1: Tesouro direto: preços e taxas dos títulos

\begin{tabular}{|c|c|c|c|c|}
\hline Título & Rentabilidade anual & Investimento mínimo & Preço Unitário & Vencimento \\
\hline TESOURO PREFIXADO 2023 & $4,29 \%$ & $R \$ 35,92$ & $\mathrm{R} \$ 898,21$ & $01 / 01 / 2023$ \\
\hline TESOURO PREFIXADO 2026 & $6,35 \%$ & $R \$ 35,51$ & $\mathrm{R} \$ 710,32$ & $01 / 01 / 2026$ \\
\hline $\begin{array}{l}\text { TESOURO PREFIXADO } \\
\text { com juros semestrais } 2031\end{array}$ & $7,01 \%$ & $R \$ 37,72$ & $\mathrm{R} \$ 1.257,60$ & $01 / 01 / 2031$ \\
\hline TESOURO SELIC 2025 & SELIC $+0,03 \%$ & $R \$ 106,24$ & $\mathrm{R} \$ 10.624,25$ & $01 / 03 / 2025$ \\
\hline TESOURO IPCA 2026 & $I P C A+2,69 \%$ & $R \$ 55,85$ & $\mathrm{R} \$ 2.792,75$ & $15 / 08 / 2026$ \\
\hline TESOURO IPCA 2035 & IPCA $+4,07 \%$ & $R \$ 36,34$ & $\mathrm{R} \$ 1.817,25$ & $15 / 05 / 2035$ \\
\hline TESOURO IPCA 2045 & IPCA $+4,07 \%$ & $R \$ 36,62$ & $\mathrm{R} \$ 1.220,79$ & $15 / 05 / 2045$ \\
\hline $\begin{array}{l}\text { TESOURO IPCA } \\
\text { com juros semestrais } 2030\end{array}$ & IPCA $+3,37 \%$ & $\mathrm{R} \$ \mathbf{4 0 , 8 0}$ & $R \$ 4.080,03$ & $15 / 08 / 2030$ \\
\hline $\begin{array}{l}\text { TESOURO IPCA } \\
\text { com juros semestrais } 2040\end{array}$ & IPCA + 3,99\% & $\mathrm{R} \$ \mathbf{4 2 , 4 9}$ & $R \$ 4.249,36$ & $15 / 08 / 2040$ \\
\hline $\begin{array}{l}\text { TESOURO IPCA }{ }^{+} \\
\text {com juros semestrais } 2055\end{array}$ & IPCA $+4,08 \%$ & $R \$ 44,61$ & $\mathrm{R} \$ 4.461,54$ & $15 / 05 / 2055$ \\
\hline
\end{tabular}

Fonte: [26]

É importante dizer que a cada dia os dados da tabela mostrada na Figura 1 sofrem alterações. Para acessar a tabela atual, ver <https://www.tesourodireto.com.br/titulos/precos-e-taxas.htm>.

Alguns conceitos importantes no ato de investir no tesouro direto são:

a) Vencimento do título: refere-se à data de resgate automático do título pelo sistema. Nessa data, o título deixa de existir e o Tesouro Nacional repassa o valor de resgate ao agente de custódia do investidor, a qual repassa para o investidor, após as deduções dos impostos e taxas, ver [29];

b) Taxa (a.a): é a rentabilidade bruta ao ano obtida, caso o título permaneça até a data de vencimento. Se o investidor optar pela venda antecipada do título, receberá o valor de mercado do mesmo, ver [29];

c) Preço unitário: refere-se ao preço de uma unidade do título vendido, porém não é necessário comprar o título inteiro, pode-se comprar frações do título. A quantidade mínima de compra é de $1 \%$ ou 0,01 do título, ver [29].

A liquidação (conclusão do processo) da compra do título não se dá na data de solicitação da compra, mas sim conforme a regra: 
a) Para uma aplicação realizada em dias úteis (de 0h00 às 18h00) a liquidação acontecerá a partir das $18 \mathrm{~h}$ do $1^{\mathrm{O}}$ dia útil após a solicitação de aplicação;

b) Para uma aplicação realizada em dias úteis (de 18h00 às 0h00), finais de semana ou feriado, a liquidação acontecerá a partir das $18 \mathrm{~h}$ do $2^{\mathrm{O}}$ dia útil após a solicitação de aplicação.

Para mais informações sobre a liquidação, ver [31].

No cálculo da rentabilidade do título é considerado apenas os dias úteis entre a data de liquidação (inclusive) e a data de vencimento (exclusive). Para mais informações sobre a metodologia de cálculo utilizada nos títulos de tesouro direto, ver [30].

No site do tesouro direto, ver [28], também encontramos alguns dos objetivos desse programa do Tesouro Nacional:

a) Garantir o acesso do cidadão ao investimento em títulos da dívida pública federal;

b) Promover a educação financeira dos brasileiros;

c) Ser referência de investimento para o cidadão;

d) Estimular a formação de poupança no país;

e) Incentivar a competitividade no mercado financeiro;

f) Ser uma alternativa de investimento conhecida e acessível.

É importante dizer que as aplicações em títulos do tesouro direto precisam ser intermediadas por uma corretora. Na plataforma do programa é possível consultar saldos e extratos, mas não é permitido aplicar sem que haja um intermediador ligando o investidor ao programa. Para isso, o investidor pode utilizar tanto os bancos múltiplos quanto corretoras que atuam com investimentos, ver [23].

Na plataforma do tesouro direto que pode ser acessado pelo site ou aplicativo no smartphone, é possível, além de consultar saldos e extratos, acessar o simulador de investimentos (ver Figura 2). É esse simulador que será o instrumento usado na abordagem do ensino de Matemática Financeira que objetivamos fazer. 
Figura 2: Simulação de investimento no site do tesouro direto
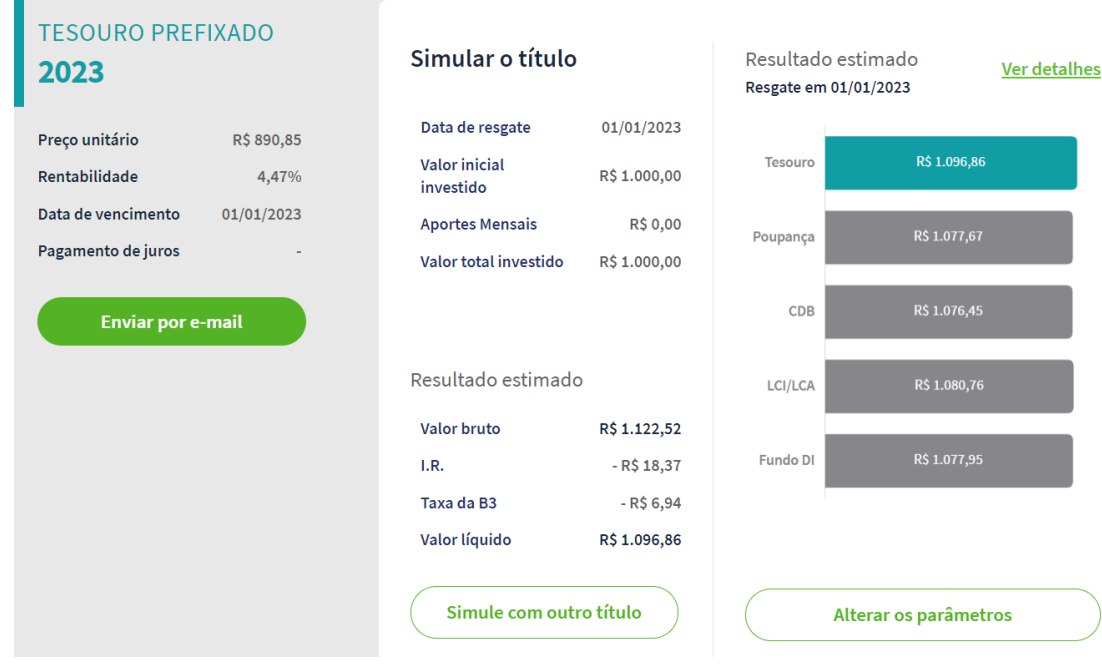

Fonte: [26]

Para acessar o simulador do tesouro direto pelo computador basta acessar o link: <https:// tesourodireto.com.br/simulador/ $>$. Também o acesso pode ser feito pelo aplicativo do tesouro direto.

\subsection{Certificado de Depósito Bancário (CDB)}

É um título emitido por bancos, corretoras e distribuidoras de títulos e valores mobiliários para captar dinheiro a fim de financiar suas atividades, tais como empréstimos a clientes, crescimento, projetos e pagamento de dívidas. No CDB o investidor empresta dinheiro para a instituição bancária. Em troca desse empréstimo, ele recebe uma rentabilidade a qual é definida no momento da compra, ver [20]. As categorias de rentabilidade do CDB são:

a) CDB prefixados: a rentabilidade já é conhecida no momento da aplicação. Por exemplo, $8 \%$ ao ano;

b) CDB pós-fixados: a rentabilidade é atrelada a um indexador da economia. O emissor paga um percentual do índice de referência utilizado, normalmente o Certificado de Depósito Interbancário (CDI). Por exemplo, $112 \%$ do CDI ao ano. Como os indexadores podem variar com o tempo, os rendimentos também sofrerão variações até o vencimento. Dessa forma, o investidor só tem uma previsão de quanto irá receber na data de resgate;

c) CDB híbridos: possui taxa de rentabilidade composta por uma parte fixa e uma parte variável, por exemplo, $2,5 \%+$ IPCA.

Além da rentabilidade, a liquidez do título é um ponto importante a se considerar antes de investir em um CDB, pois muitos só permitem resgate na data de vencimento. Quanto à segurança, o CDB conta com a proteção do FGC. Dessa forma, se a instituição que emitiu o CDB decretar falência, o dinheiro do investidor, dentro das condições do fundo, estará assegurado, ver [20]. 
Assim como nos títulos do tesouro direto, se houver resgate em menos de 30 dias de aplicação, haverá incidência de IOF sobre os rendimentos, ver [20]. E no momento de resgate haverá a incidência de IR sobre os rendimentos, conforme abaixo:

- Aplicações até 6 meses: 22,5\%;

- Aplicações de 6 meses a 1 ano: 20\%;

- Aplicações de 1 ano a 2 anos: 17,5\%;

- Aplicações a mais de 2 anos: $15 \%$.

\subsection{Letra de Crédito do Agronegócio (LCA)}

A Letra de Crédito do Agronegócio (LCA) é um título privado emitido por instituições financeiras com prazo e taxa definidos no momento da compra, ver [11]. Os recursos captados pelo emissor são utilizados para o financiamento das atividades do setor agrícola. O que a torna bastante interessante é a isenção de IR e de IOF para pessoas físicas, além de contar com a cobertura do FGC em até $\mathrm{R} \$ 250.000,00$ por emissor e por CPF, ver [11].

\subsection{Letra de Crédito do Imobiliário (LCI)}

A Letra de Crédito Imobiliário (LCI) é um título privado emitido por instituições financeiras com prazo e taxa definidos no momento da compra, ver [12]. Os recursos captados pelo emissor são utilizados para o financiamento das atividades do setor imobiliário. Assim como nas LCAs, as LCIs têm isenção de IR e de IOF além de contar com a cobertura do FGC em até R $\$ 250.000,00$ por emissor e por CPF, ver [12].

Como se pode ver, a LCI e LCA são bem parecidas, dessa forma o investidor costuma decidir entre elas baseado tão somente na taxa de rendimento, no prazo de investimento e no valor mínimo para aplicação inicial.

\section{Proposta de atividades via simulador do Tesouro Direto}

Nesta seção vamos propor uma abordagem de ensino de Matemática Financeira para o Ensino Médio, mediante apresentação de duas atividades que relacionam problemas envolvendo simulações de investimentos no tesouro direto, ver [32], e alguns conceitos matemáticos. Além disso, revelamos um possível percurso de resolução de cada atividade. Observamos que, ao utilizarmos o site do tesouro direto em tempo real, os títulos disponíveis e as taxas mudam a cada dia, bem como o próprio site passa por periódicas atualizações, podendo assim alterar algum percurso de alguma ferramenta.

É importante dizer que não é o objetivo dessa proposta abordar todos os aspectos relacionados aos cálculos dos investimentos em títulos públicos, devido ao grau de dificuldade que estaria sendo exposto aos alunos do nível médio. Portanto, os alunos farão simulações pelo site do tesouro direto e realizarão cálculos aproximados, desconsiderando-se aspectos como dias úteis de um determinado período e cobranças de taxas. Para uma leitura sobre a metodologia de cálculo da rentabilidade dos investimentos do tesouro direto, recomendamos ver [30].

A seguir, vamos descrever cada atividade e sua respectiva proposta de resolução. 
Atividade 1.

(a) Uma pessoa possui $\mathrm{R} \$ 250,00$ para investir em um título público. Usando o site do tesouro direto <https://www.tesourodireto.com.br/>, faça uma simulação de uma aplicação com essa quantia no tesouro Selic 2025 (trata-se da opção (a) da p.651). Qual o valor em reais que ela receberá ao final do vencimento? Se dobrarmos o valor de aplicação, qual será o valor líquido que ela irá receber? Compare o resultado de cada caso com a rentabilidade na caderneta de poupança.

(b) Atualmente, os juros pagos pela caderneta de poupança dependem do valor da taxa Selic, com o acréscimo da Taxa Referencial (TR), seguindo as seguintes regras:

(i) Se a taxa Selic for superior a 8,5\% ao ano, então a remuneração da poupança será de $0,5 \%$ ao mês mais a TR;

(ii) Caso a taxa Selic seja igual ou menor do que 8,5\% ao ano, o rendimento da poupança será de $70 \%$ da taxa Selic mais a TR.

Se a taxa Selic está atualmente a $2 \%$ a.a. e a taxa de referencial está em $0 \%$ ao ano, então qual é a taxa de juros atual da caderneta de poupança?

\section{Resolução da Atividade 1.}

(a) O aluno irá acessar o site do tesouro direto por meio do link

$$
\text { <https://www.tesourodireto.com.br/>. }
$$

Após o acesso, seu próximo passo será dar início a sua simulação. Para isso, ele deverá clicar na aba "Simulador" (ver Figura 3).

Figura 3: Visualização do site do tesouro direto

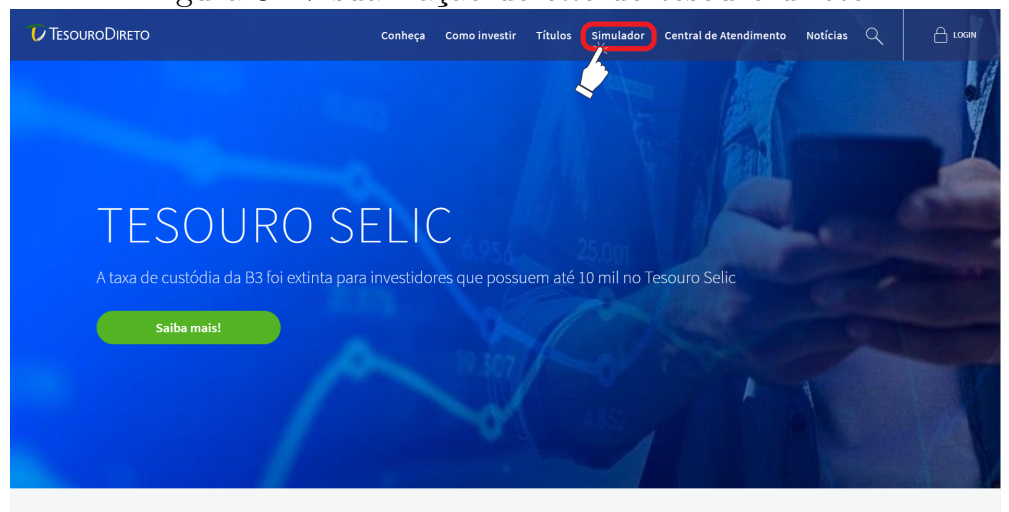

SIMULE SEU INVESTIMENTO

Fonte: [32]

Posteriormente, o aluno será redirecionado para uma página intitulada como "orientador financeiro" e, consequentemente, deverá escolher entre "Vamos começar?" e "Já escolhi meu título". Como queremos uma aplicação do tesouro Selic 2025, o aluno deverá clicar na opção "Já escolhi meu título" (ver Figura 4). 
Figura 4: Orientador financeiro

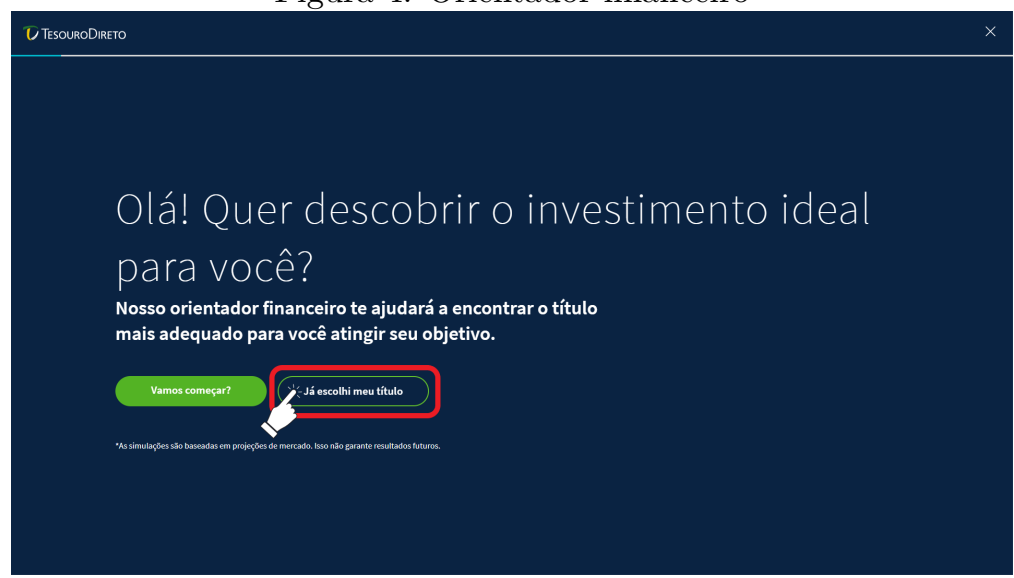

Fonte: [32]

A partir daí, o aluno deverá deslizar a barra rolante da tela para ter acesso a uma tabela, a qual exibe os títulos disponíveis para venda naquele dia. Além disso, ele precisará localizar o termo "TESOURO SELIC 2025" localizado na primeira coluna da tabela e, então, clicar em "Simule", o qual se encontra na mesma linha, em verde (ver Figura 5).

Figura 5: Escolha do título tesouro Selic 2025

\begin{tabular}{|c|c|c|c|c|c|c|c|}
\hline U TESOURODIRETO & & Conheça c & o investir Títulos & Simulador & Entral de Atendimento & Noticias $Q$ & $\theta$ юесм \\
\hline Titulo & & Rentabilidade anual & Investimento minimo & Preço Unitário & Vencimento & & \\
\hline TESOURO PREFIXADO 2023 & (?) & $5,04 \%$ & R\$ 35,99 & R\$ 899,99 & $01 / 01 / 2023$ & Simule & \\
\hline TESOURO PREFIXADO 2026 & ?) & $7,15 \%$ & R\$ 35,05 & $R \$ 701,05$ & $01 / 01 / 2026$ & Simule & \\
\hline \begin{tabular}{l|l} 
TESOURO PREFIXADO \\
com juros semestrais 2031
\end{tabular} & (?) & $7,52 \%$ & R\$ 36,11 & R\$1.203,95 & $01 / 01 / 2031$ & Simule & \\
\hline TESOURO SELIC 2025 & ?) & SELLC $+0,1950 \%$ & $R \$ 106,40$ & R\$10.640,60 & $01 / 03 / 2025$ & simule & \\
\hline TESOURO IPCA' 2026 & (?) & $\mathrm{IPCA}+2,83 \%$ & $R \$ 57,26$ & $R \$ 2.863,34$ & $15 / 08 / 2026$ & simule & \\
\hline TESOURO IPCA' 2035 & $?$ & IPCA $+3,97 \%$ & R\$ 38,29 & R\$1.914,67 & $15 / 05 / 2035$ & Simule & \\
\hline TESOURO IPCA' 2045 & (?) & IPCA $+3,97 \%$ & R\$ 38,95 & R\$1.298,62 & $15 / 05 / 2045$ & Simule & \\
\hline $\mid \begin{array}{l}\text { TESOURO IPCA } \\
\text { com juros semestrais } 2030\end{array}$ & ? ? & $\mathrm{IPCA}+3,32 \%$ & $R \$ 41,42$ & $R \$ 4.142,81$ & $15 / 08 / 2030$ & Simule & \\
\hline \begin{tabular}{||l} 
TESOURO IPCA \\
com juros semestrais 2040
\end{tabular} & (?) & IPCA $+3,94 \%$ & $\mathrm{R} \$ 43,40$ & $R \$ 4.340,03$ & $15 / 08 / 2040$ & Simule & \\
\hline \begin{tabular}{l|l} 
TESOURO IPCA \\
com juros semestrais 2055
\end{tabular} & ? ? & $\mathrm{IPCA}+4,16 \%$ & Rs 45,75 & $R \$ 4.575,47$ & $15 / 05 / 2055$ & Simule & \\
\hline
\end{tabular}

O estudante, então, será direcionado à página de simulação, onde receberá algumas informações do título escolhido, alinhadas à esquerda da tela. O site exibirá o preço unitário, a rentabilidade e a data de vencimento. Ademais, em destaque, o aluno terá a oportunidade de realizar a simulação desse título. Para isso, o discente deverá escolher entre "Quanto quero investir hoje" e "Quanto quero resgatar no futuro". Para realizar a atividade, o aluno precisa clicar na primeira opção "Quanto quero investir hoje" (ver Figura 6). 
Figura 6: Escolha do tipo de simulação do tesouro Selic 2025

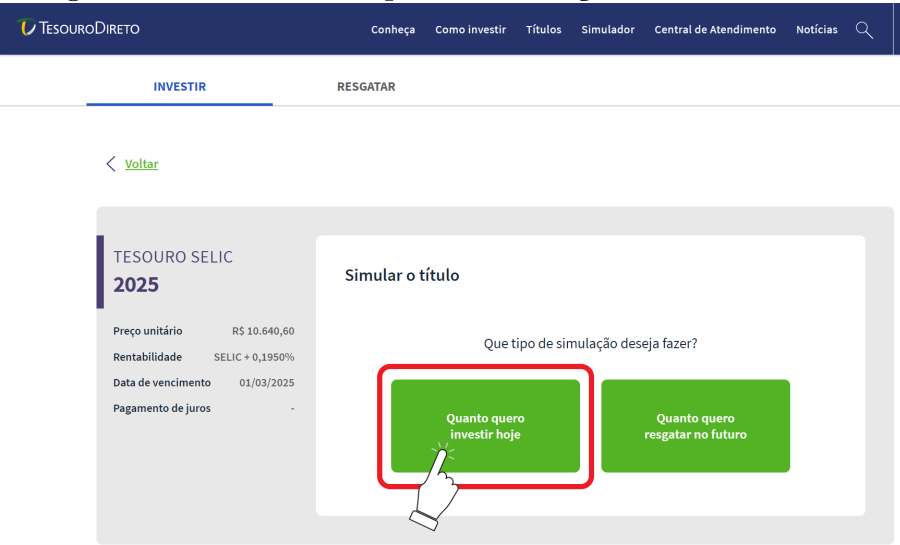

Fonte: [26]

Agora, o aluno poderá digitar o valor que ele pretende investir (ver Figura 7). Observamos que são exibidos dois campos para preenchimento: o campo "Qual o valor que você quer investir", onde ele aplicará um valor específico de uma única vez, e o outro campo que será preenchido caso o aluno queira realizar uma aplicação mensal. No caso em questão, ele fará a simulação de $\mathrm{R} \$ 250,00$ no primeiro campo de preenchimento (ver Figura 7).

Figura 7: Escolha o valor a investir no tesouro Selic 2025

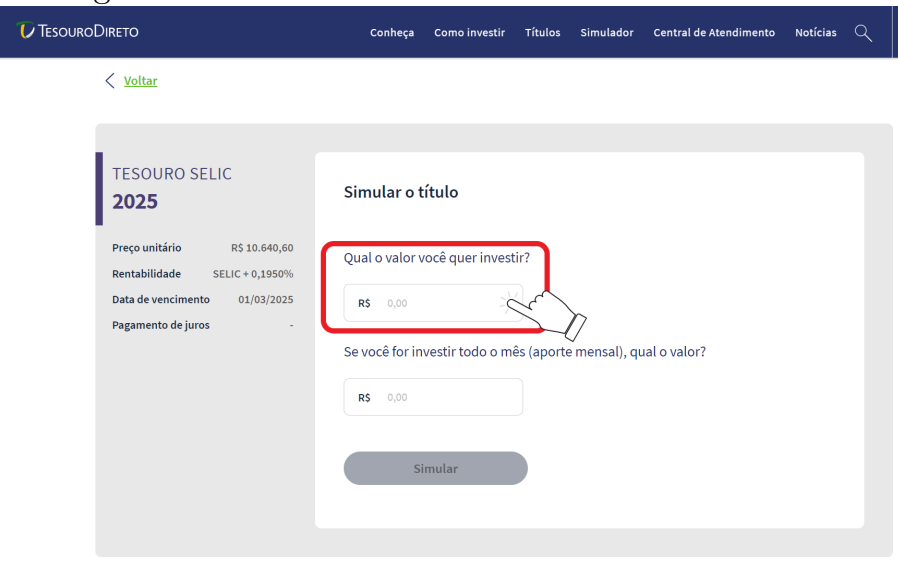

Fonte: [26]

Neste momento, o aluno poderá digitar no campo exibido o valor de $\mathrm{R} \$ 250,00$. Destacamos que assim que ele inserir o valor escolhido, o botão "Simular" ficará verde, sinalizando que ele poderá realizar sua simulação e obter os dados. Para isso, o aluno deverá clicar em "Simular" (ver Figura 8). 
Figura 8: Simular $\mathrm{R} \$ 250,00$ no tesouro Selic 2025

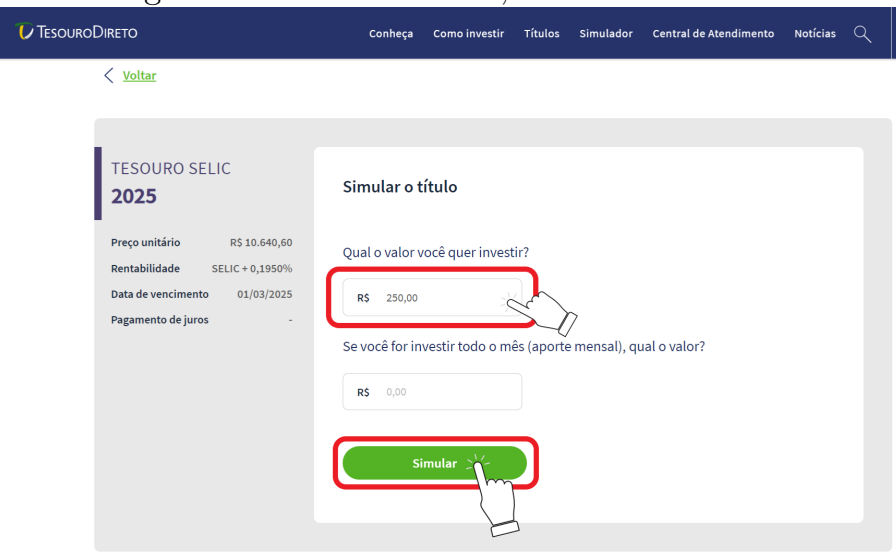

Fonte: [26]

Finalmente, o aluno terá acesso à sua simulação. Destacamos que é oferecido um gráfico e outras informações, a saber, data de resgate e valor inicial investido, bem como o resultado estimado (ver Figura 9). Ademais, é feita a comparação com outras modalidades de investimentos do mercado financeiro no mesmo período simulado (ver Figura 9).

Figura 9: Resultado da simulação tesouro Selic 2025

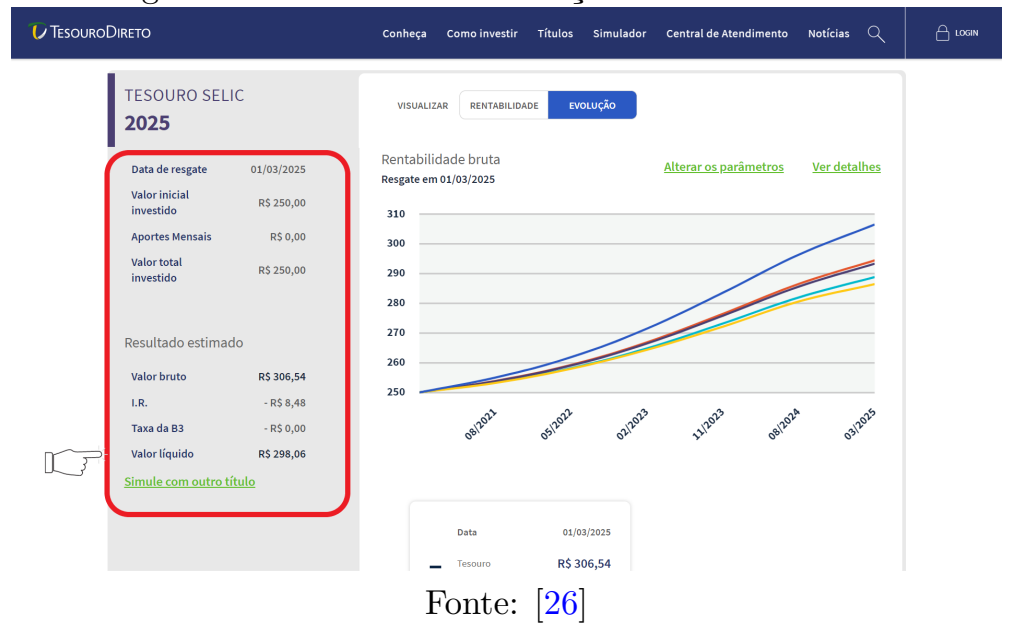

De acordo com a Figura 9, o valor líquido do tesouro Selic 2025 será de R $\$ 298,06$. Movendo a barra de rolagem da tela para baixo, visualizamos uma tabela de comparação com outros tipos de investimentos, dentre eles podemos ver que o valor obtido na poupança nesse mesmo período será de R $\$ 286,46$ (ver Figura 10). Ademais, aparecerá a opção escolher entre investir ou enviar o resultado por e-mail. 
Figura 10: Comparação com outros investimentos

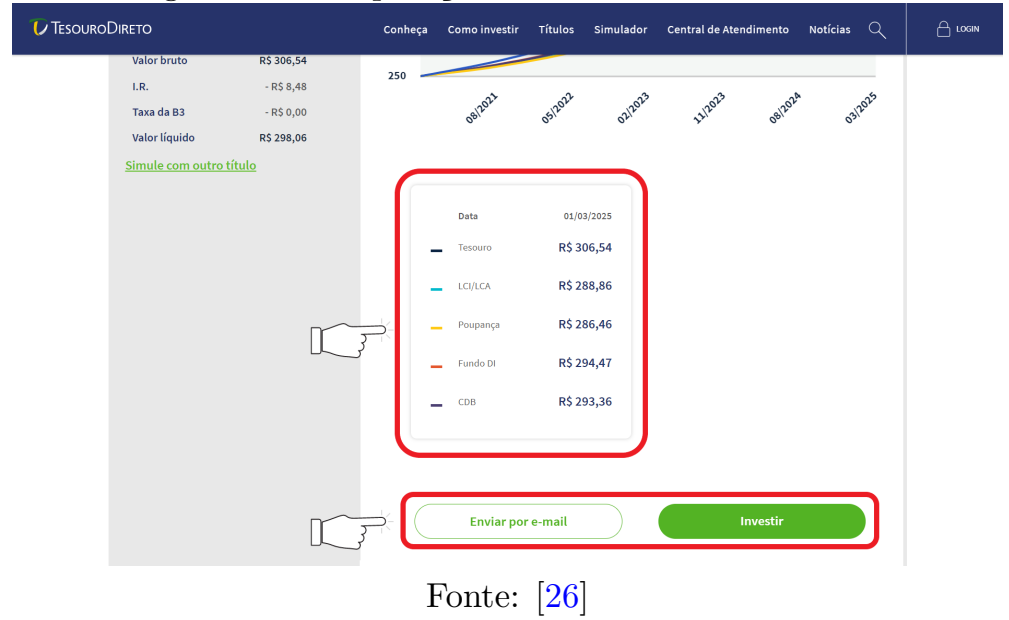

Além disso, clicando em "rentabilidade" (ver Figura 11), será exibido um gráfico de barras comparando o título com outros tipos de investimentos (ver Figura 12).

Figura 11: Clicando em "rentabilidade"

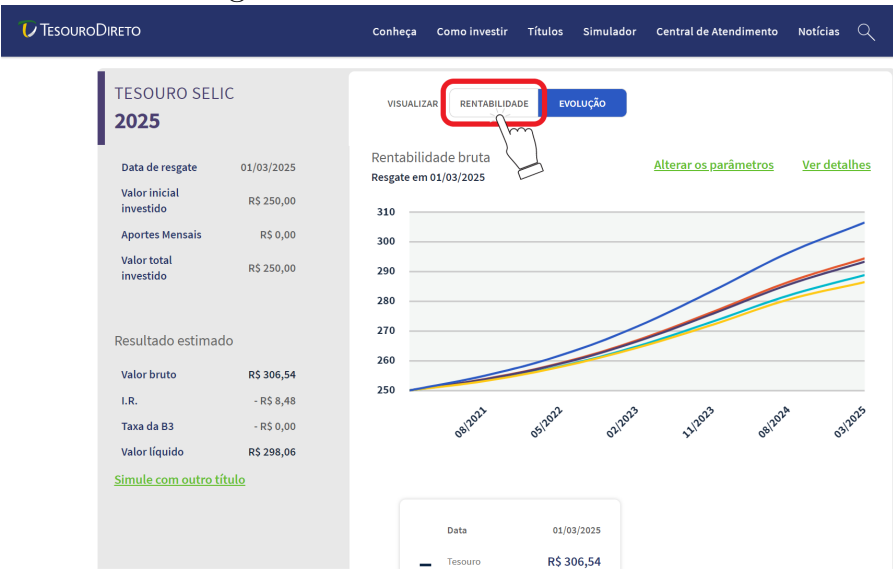

Fonte: [26]

Na Figura 11, verificamos também um gráfico de linhas comparando o comportamento do valor bruto de uma aplicação de R $\$ 250,00$ no tesouro Selic 2025 com outros investimentos durante o mesmo período de tempo. Cada cor das linhas está relacionada a um investimento; essa relação pode ser verificada na tabela ilustrada na Figura 10. 
Figura 12: Gráfico de barras tesouro Selic

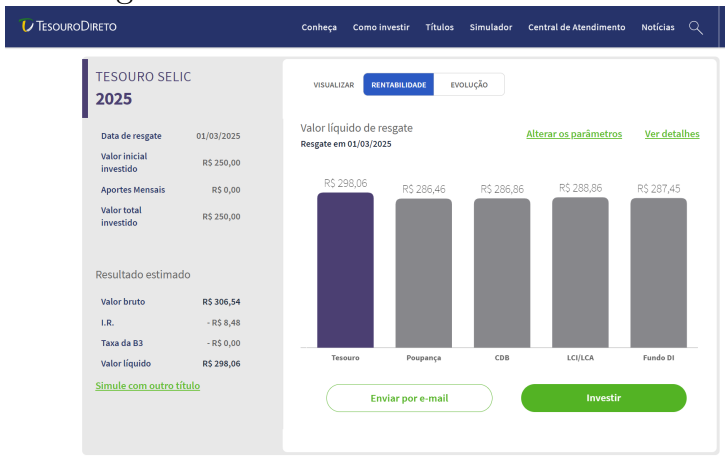

Fonte: [26]

O gráfico de barras, ilustrado na Figura 12, compara o valor líquido de resgate estimado no tesouro Selic 2025 com o valor líquido nos investimentos: poupança, CDB, LCI/LCA e Fundos DI. Note que nessa situação a poupança tem valor líquido menor do que todos os investimentos indicados no gráfico. Importante dizer que no mercado financeiro é possível encontrar CDBs, LCIs/LCAs e Fundos DI com rentabilidade maior do que a do tesouro Selic. Pelo gráfico de barras também vemos que o valor líquido estimado do investimento do tesouro Selic foi de $\mathrm{R} \$ 298,06$. Dessa forma, ao investir $\mathrm{R} \$ 250,00$, nesse contexto, ele receberá $\mathrm{R} \$$ 48,06 a mais ao final do período. Esse valor representa o valor nominal recebido, isto é, não é considerado o efeito da inflação no período.

Agora, para fazer a simulação do dobro de $\mathrm{R} \$ 250,00$, isto é, $\mathrm{R} \$ 500,00$, o aluno poderá clicar em "voltar" (ver Figura 13).

Figura 13: Clicando em "voltar"

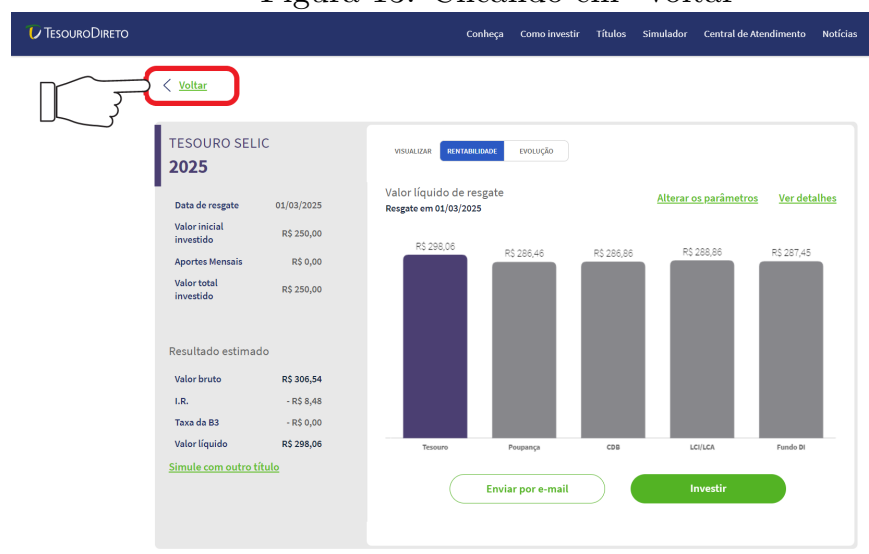

Fonte: [26]

Após clicar, ele voltará para a tela de escolha do valor a investir (ver Figura 7). Então, ele digitará 500,00 no primeiro campo e clicará em "Simular" (ver Figura 14). 
Figura 14: Simular R $\$ 500,00$ no tesouro Selic 2025

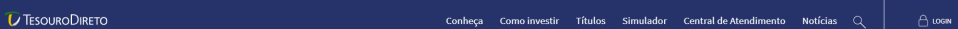

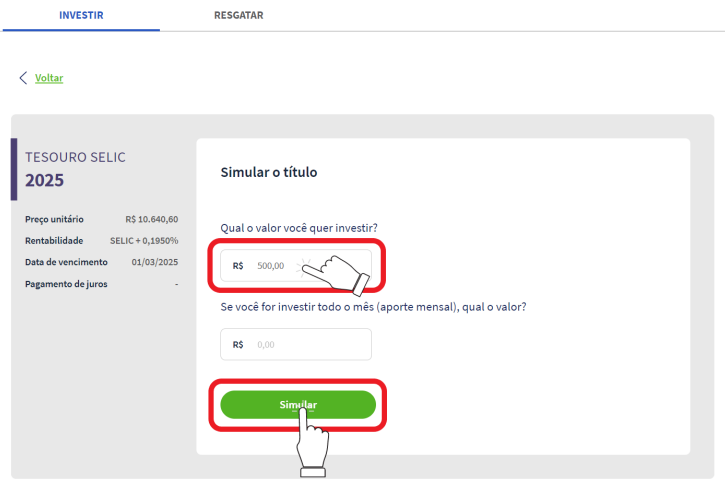

Fonte: [26]

Após clicar em "Simular" ele será direcionado para página com o resultado da simulação (ver Figura 15).

Figura 15: Resultado da simulação de $\mathrm{R} \$ 500,00$ no tesouro Selic 2025
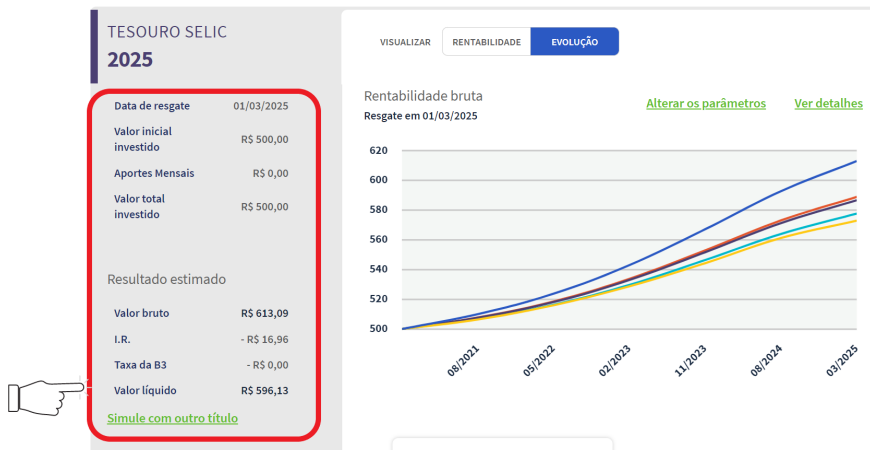

Fonte: [26]

De acordo com a Figura 15, o valor líquido será de $\mathrm{R} \$$ 596,13. Nessa figura, também podemos visualizar outras informações, como a data de resgate, valor inicial investido, aportes mensais, imposto de renda e taxa B3. Ao centro da figura, há um gráfico de linhas comparando o comportamento do valor bruto de uma aplicação de $\mathrm{R} \$ 500,00$ no tesouro Selic 2025 com outros investimentos (poupança, CDB, LCI/LCA, e Fundos DI) durante o mesmo período de tempo. Cada cor das linhas está relacionada a um investimento; essa relação pode ser verificada na tabela ilustrada na Figura 16. Movendo a barra de rolagem da tela para baixo, visualizamos a tabela de comparação, na qual podemos ver que o valor obtido na poupança nesse mesmo período será de $\mathrm{R} \$ 572,92$ (ver Figura 16). 
Figura 16: Tabela de comparação

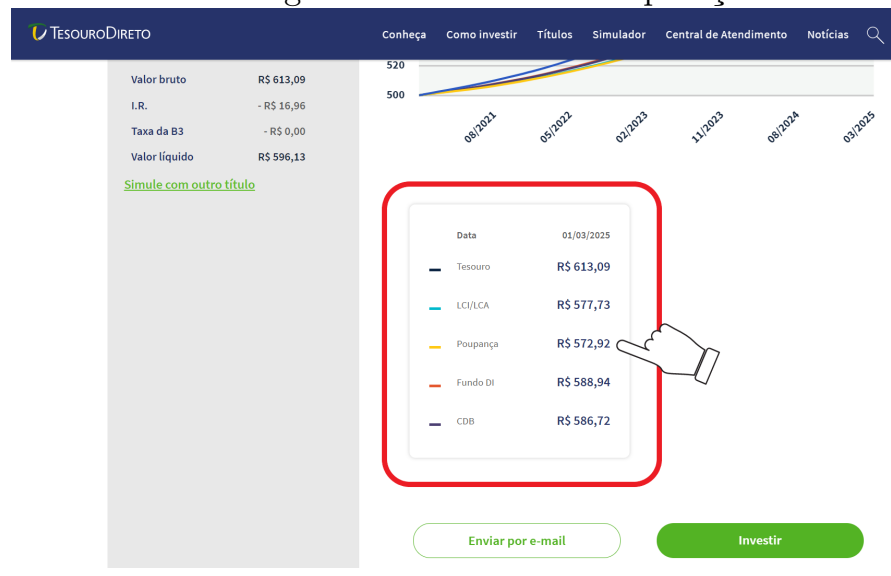

Fonte: [26]

A tabela indicada na Figura 16 compara o valor bruto obtido no tesouro Selic 2025 com o valor bruto de outros investimentos: poupança, CDB, LCI/LCA e Fundos DI. Note que, nessa situação, novamente a poupança tem valor menor do que todos os investimentos indicados na tabela.

(b) Como a taxa Selic está a 2\%a.a., a rentabilidade da caderneta de poupança está sendo baseada na segunda regra: caso a taxa Selic seja igual ou menor do que 8,5\% ao ano, o rendimento da poupança será de $70 \%$ da taxa Selic mais a TR. Dessa forma o rendimento será

$$
0,7 \times 2+\mathrm{TR}=1,4+0=1,4
$$

Portanto, o rendimento está em 1,4\%a.a.

Atividade 2.

(a) Identifique a taxa de rentabilidade anual e o vencimento do tesouro prefixado 2023. Em seguida, expresse, em anos, meses e dias, o período em que o dinheiro permanecerá aplicado até a data de vencimento ( $\mathrm{X}$ anos, $\mathrm{Y}$ meses e $\mathrm{Z}$ dias).

(b) Utilizando o período de aplicação encontrado no item (a) e a taxa de rentabilidade anual do tesouro prefixado 2023, calcule uma aproximação do montante, no regime de juros compostos, de uma aplicação de $\mathrm{R} \$ 52,00$ no tesouro prefixado 2023 (para isso desconsidere a cobrança de taxas). Após os cálculos, faça uma simulação de R \$52,00 no tesouro prefixado 2023 e compare os resultados.

(c) Calcule o montante de uma aplicação de $\mathrm{R} \$ 52,00$, no regime de juros simples, obtido no mesmo período e com a mesma taxa de rentabilidade do item (a). Qual a diferença dos montantes encontrados no regime de juros simples e compostos?

\section{Resolução da Atividade 2.}

(a) O aluno irá acessar o site do tesouro direto por meio do link 
Após o acesso, seu próximo passo será dar início a sua simulação. Para isso, ele deverá clicar na aba "Simulador" (ver Figura 3).

Posteriormente, o aluno será redirecionado para uma página intitulada como "orientador financeiro" e, consequentemente, deverá escolher entre "Vamos começar?" e "Já escolhi meu título". Como queremos uma aplicação do tesouro prefixado 2023, o aluno deverá clicar na opção "Já escolhi meu título" (ver Figura 4).

A partir daí, o aluno deverá deslizar a barra rolante da tela para ter acesso a uma tabela, a qual exibe os títulos disponíveis para venda naquele dia. Além disso, ele precisará localizar o termo "Tesouro Prefixado 2023" localizado na primeira coluna da tabela (ver Figura 17).

Figura 17: Localização do termo "tesouro prefixado 2023"

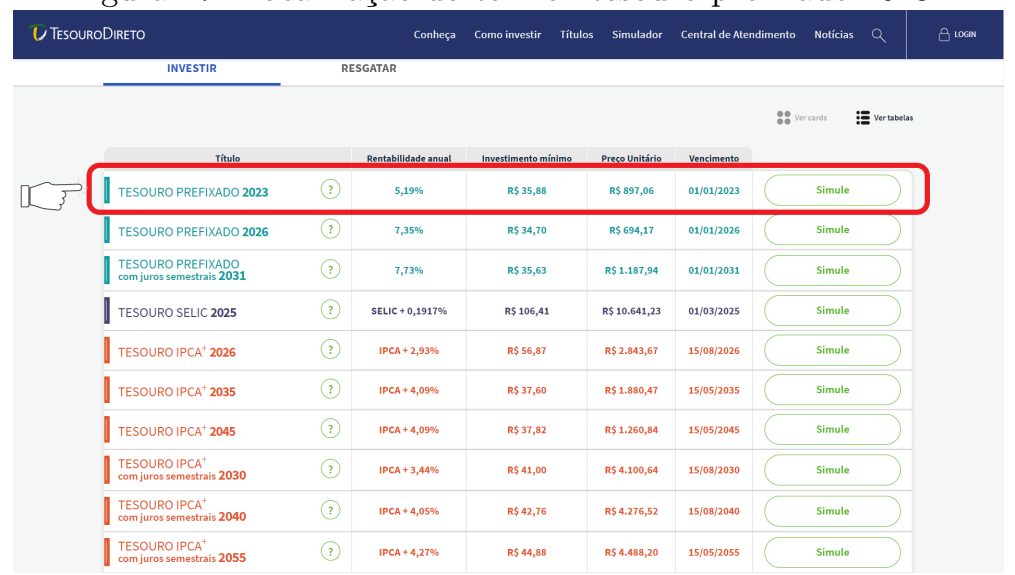

Fonte: [26]

Na linha do tesouro prefixado 2023, ele identifica a taxa rentabilidade anual e o vencimento desse título, os quais se encontram na segunda e quarta coluna, respectivamente (ver Figura 18).

Figura 18: Rentabilidade anual e Vencimento do tesouro prefixado 2023

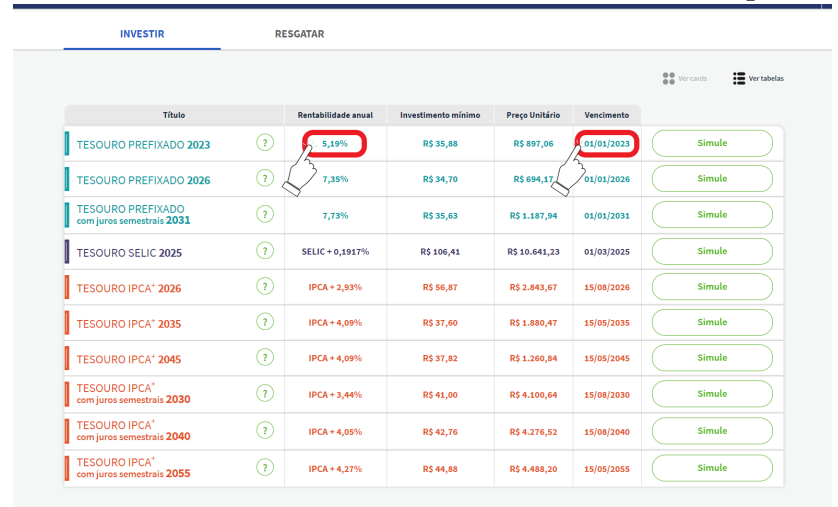

Fonte: [26] 
De acordo com a Figura 18, a taxa de rentabilidade anual é de 5,19\%a.a. e o vencimento do título será no dia 01/01/2023. Como a aplicação está sendo simulada no dia 05/11/2020, o período de investimento será contado a partir do dia 06/11/2020. Para expressar o período de aplicação em anos, meses e dias, uma possibilidade é o aluno perceber que do dia 06/11/2020 (inclusive) ao dia 05/11/2022 (inclusive) há 2 anos. E do dia 06/11/2022 (inclusive) ao dia 05/12/2022 (inclusive) há 1 mês. Assim, contando a partir do dia 06/12/2022, faltam apenas 26 dias para o vencimento, pois o dinheiro não recebe incidência de juros no dia do vencimento (01/01/2023). Podemos visualizar a quantidade de dias restantes na Figura 19.

Figura 19: Dias restantes entre 06/11 a 31/12 de 2022

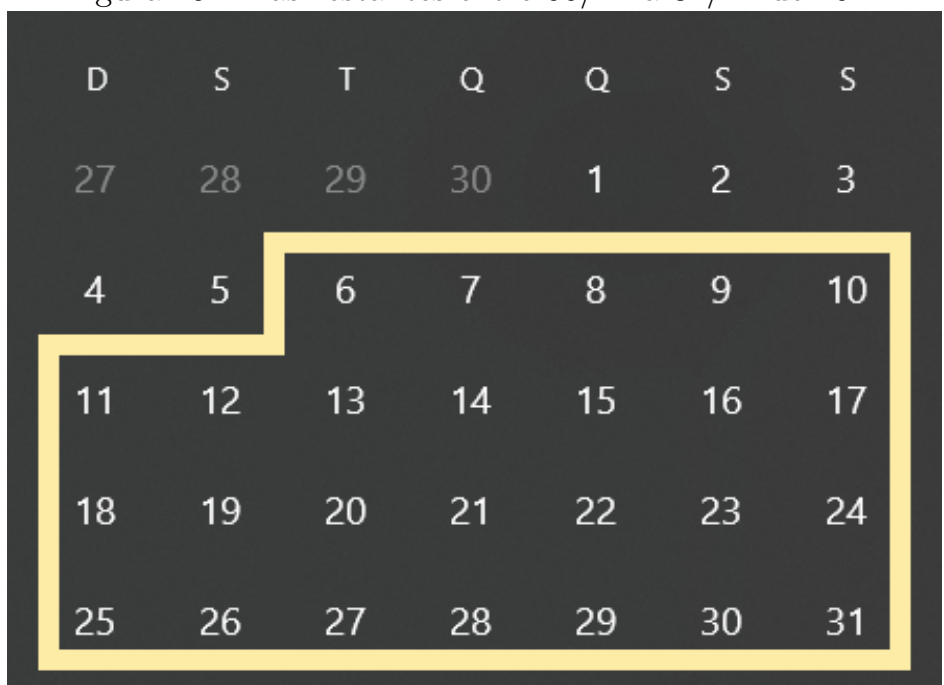

Fonte: Autoria própria

Portanto, o período de investimento será de 2 anos, 1 mês e 26 dias. Com isso, concluímos o item (a).

(b) Vamos calcular o montante em três etapas. Inicialmente, devemos encontrar o montante referente aos 2 primeiros anos de investimento, o qual chamaremos $M_{1}$, para em seguida calcular a rentabilidade em um mês (06/11/2022 a 05/12/2022) e, finalmente, nos últimos 26 dias, que denominaremos $\mathrm{M}_{2}$ e $\mathrm{M}_{\mathrm{c}}$, respectivamente. Para maior clareza dos cálculos utilizados aqui, sugerimos a leitura do apêndice ao final do artigo.

Como a taxa de rentabilidade anual $\left(\mathrm{i}_{\mathrm{a}}\right)$ é de $5,19 \%$ e o capital inicial investido $\left(\mathrm{c}_{1}\right)$ é de $\mathrm{R} \$$ 52,00 , substituindo $\mathrm{i}_{\mathrm{a}}=0,0519$ e $\mathrm{c}_{1}=52$ em $\mathrm{M}_{1}=\mathrm{c}_{1}\left(1+\mathrm{i}_{\mathrm{a}}\right)^{2}$, obtemos

$$
\mathrm{M}_{1}=52(1+0,0519)^{2}=57,53766772,
$$

isto é, $\mathrm{M}_{1} \approx \mathrm{R} \$ 57,54$.

Agora, a partir do capital $c_{2}=M_{1}$, calcularemos o montante acumulado $\mathrm{M}_{2}$ referente a um mês de aplicação. Para isso, devemos encontrar uma taxa mensal $i_{m}$ equivalente à taxa anual $\mathrm{i}_{\mathrm{a}}$. Portanto, utilizamos a equação $1+\mathrm{i}_{\mathrm{a}}=\left(1+\mathrm{i}_{\mathrm{m}}\right)^{12}$, ou seja,

$$
\mathrm{i}_{\mathrm{m}}=\left(1+\mathrm{i}_{\mathrm{a}}\right)^{\frac{1}{12}}-1 \text {. }
$$


Logo, substituindo $\mathrm{i}_{\mathrm{a}}=0,0519$, obtemos

$$
\mathrm{i}_{\mathrm{m}}=(1+0,0519)^{\frac{1}{12}}-1 .
$$

Lançando mão de uma calculadora científica, encontramos $\mathrm{i}_{\mathrm{m}}=0,004225406$.

Agora, substituindo $\mathrm{c}_{2}=57,54$ e $\mathrm{i}_{\mathrm{m}}=0,004225406 \mathrm{em} \mathrm{M}_{2}=\mathrm{c}_{2}\left(1+\mathrm{i}_{\mathrm{m}}\right)$, temos

$$
\mathrm{M}_{2}=57,54(1+0,0042225406)=57,783129861 .
$$

Daí, $\mathrm{M}_{2} \approx \mathrm{R} \$ 57,78$.

Finalmente, a partir do capital $c_{3}=M_{2}$, calculemos o montante acumulado referente aos 26 dias restantes de investimento, o qual denominamos de $\mathrm{M}_{\mathrm{c}}$. Para isso, calculamos a taxa diária, $i_{d}$, equivalente à taxa mensal $i_{m}$.

Fazendo $i_{\mathrm{m}}=0,004225406$, encontramos

$$
\mathrm{i}_{\mathrm{d}}=(1+0,004225406)^{\frac{1}{30}}-1=0,00014056 .
$$

Substituindo $c_{3}=57,78$ e $i_{d}=0,00014056$ em $M_{c}=c_{3}\left(1+i_{d}\right)^{26}$, obtemos

$$
\mathrm{M}_{\mathrm{c}}=57,78(1+0,00014056)^{26}=57,991531903 .
$$

Logo, $\mathrm{M}_{\mathrm{c}} \approx \mathrm{R} \$ 58,00$.

Na segunda etapa, após realizar os passos exibidos nas figuras 3, 4 e 17, o aluno clicará em "Simule" (ver Figura 20).

Figura 20: Escolha de título, clique em "Simule"

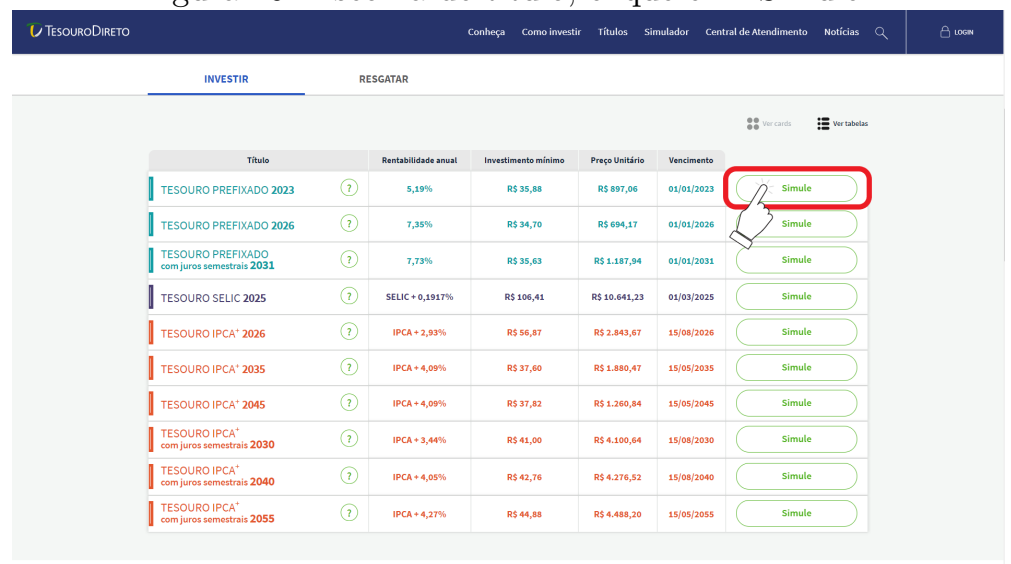

Fonte: [26]

O estudante será direcionado à página de simulação, onde receberá algumas informações do título escolhido, alinhadas à esquerda da tela. O site exibirá o preço unitário, a rentabilidade e a data de vencimento. Ademais, em destaque, o aluno terá a oportunidade de realizar a simulação desse título. Para isso, o discente deverá escolher entre "Quanto quero investir hoje" e "Quanto quero resgatar no futuro". Para realizar a atividade, o aluno precisa clicar na primeira opção "Quanto quero investir hoje" (ver Figura 21). 
Figura 21: Escolha do tipo de simulação do tesouro prefixado 2023

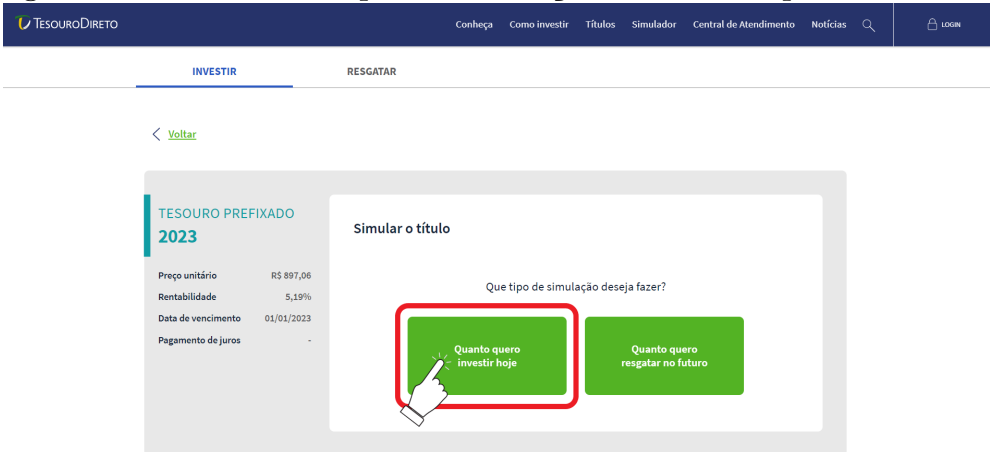

Fonte: [26]

Agora, o aluno poderá digitar o valor que ele pretende investir (ver Figura 22). Observamos que são exibidos dois campos para preenchimento: o campo "Qual o valor que você quer investir", onde ele aplicará um valor específico de uma única vez, e o outro campo que será preenchido caso o aluno queira realizar uma aplicação mensal. No caso em questão, ele fará a simulação de $\mathrm{R} \$ 52,00$ no primeiro campo de preenchimento (ver Figura 22).

Figura 22: Escolha do valor a investir

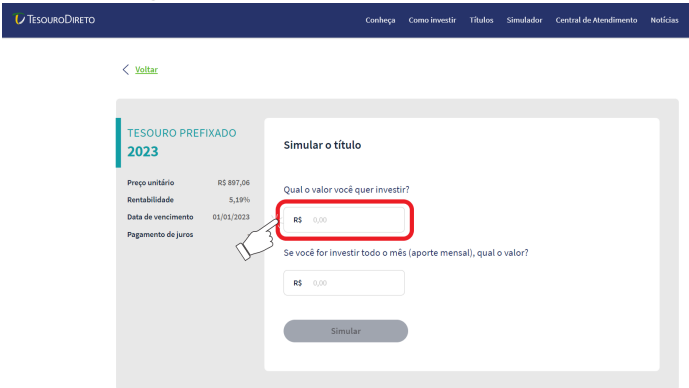

Fonte: [26]

Neste momento, o aluno poderá digitar no campo (ver Figura 23) o valor de R\$52,00. Destacamos que assim que ele inserir o valor escolhido, o botão "Simular"ficará verde, sinalizando que ele poderá finalizar sua simulação e obter o resultado. Para isso, o aluno deverá clicar em "Simular" (ver Figura 23). 
Figura 23: Finalizar a simulação tesouro prefixado 2023

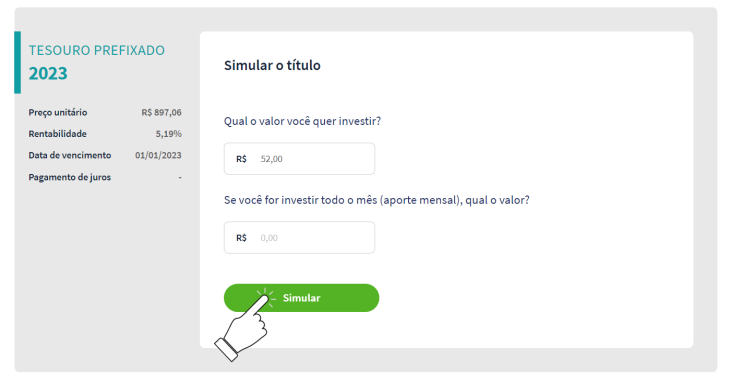

Fonte: [26]

Após clicar em "Simular", ele será redirecionado para o resultado de sua simulação (ver Figura 24).

Figura 24: Resultado da simulação tesouro prefixado 2023

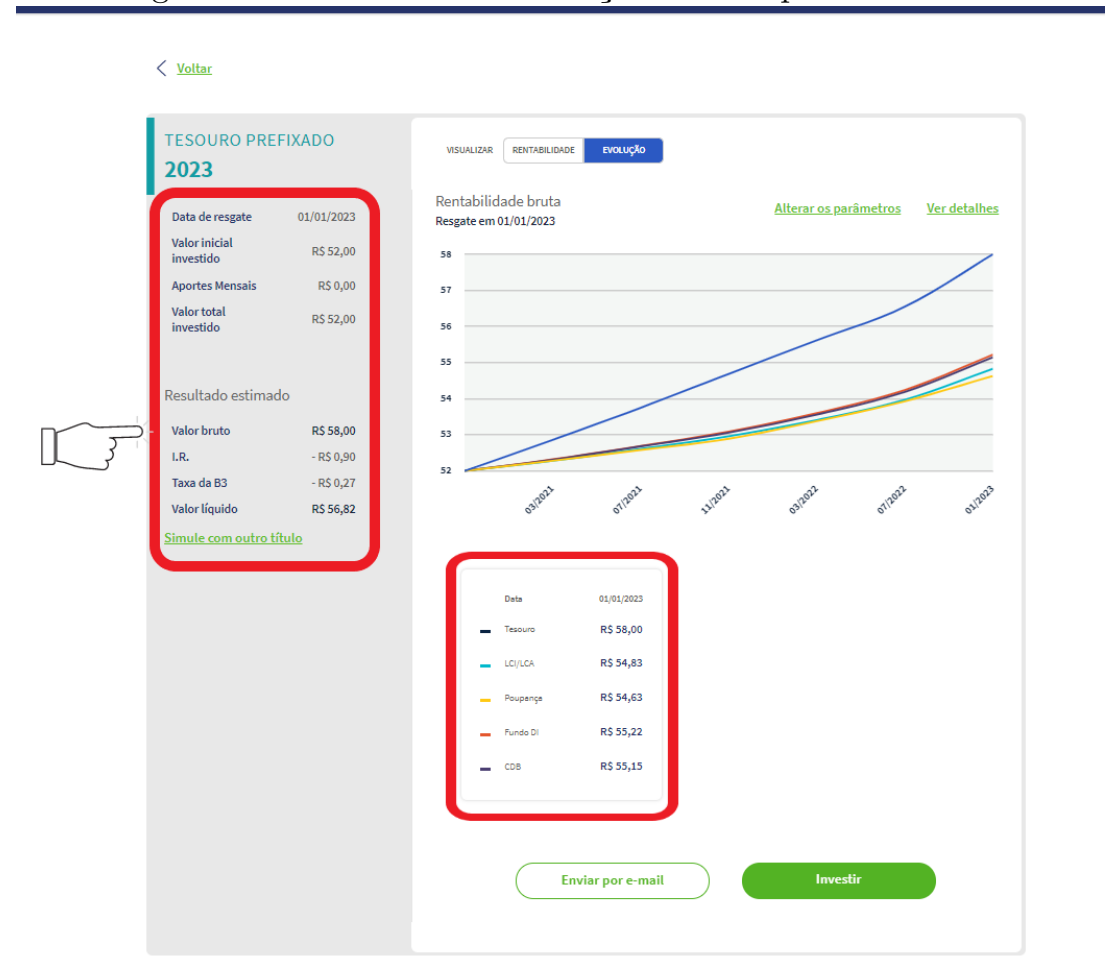

Fonte: [26]

De acordo com a Figura 24, o valor bruto obtido foi de $\mathrm{R} \$ 58,00$, ratificando, assim, o cálculo realizado inicialmente com as conversões da rentabilidade e a atualização do montante.

(c) Procederemos por um percurso diferente do item (b). Novamente, para um maior entendi- 
mento dos conceitos utilizados nesse item, sugerimos a leitura do apêndice ao final do artigo. Inicialmente, observe que o período total de investimento é 25 meses e 26 dias.

Logo, substituindo $c_{1}=52 \mathrm{e}, \mathrm{i}_{\mathrm{m}}=\frac{\mathrm{i}_{\mathrm{a}}}{12}=\frac{0,0519}{12}=0,004325 \mathrm{em} \mathrm{M}_{1}=\mathrm{c}_{1}\left(1+\mathrm{i}_{\mathrm{m}} \times 25\right)$, obtemos

$$
\mathrm{M}_{1}=52(1+0,004325 \times 25)=57,6225,
$$

ou seja, $\mathrm{M}_{1} \approx \mathrm{R} \$ 57,62$.

A partir de $\mathrm{M}_{1}$, calculemos o montante acumulado após 26 dias, o qual chamaremos de $\mathrm{M}_{\mathrm{s}}$. Para isso, substituímos $\mathrm{i}_{\mathrm{d}}=\frac{\mathrm{i}_{\mathrm{m}}}{30}=\frac{0,004325}{30}=0,000144167$ e $\mathrm{c}_{2}=\mathrm{M}_{1}=57,62 \mathrm{em}$ $\mathrm{M}_{\mathrm{s}}=\mathrm{c}_{2}\left(1+\mathrm{i}_{\mathrm{d}} \times 26\right)$.

Portanto,

$$
\mathrm{M}_{\mathrm{s}}=57,62(1+0,000144167 \times 26)=57,835979466 .
$$

Assim, $\mathrm{M}_{\mathrm{s}} \approx \mathrm{R} \$ 57,84$.

Portanto, a diferença entre os montantes encontrados no regime de juros simples e compostos é de

$$
58-57,84=0,16
$$

\section{Apêndice}

\subsection{Juro}

O juro (j) é a remuneração recebida por quem dispõe de um capital c e o empresta durante certo período a alguém. A soma $c+j$ é chamada de montante e é representada por M. A razão i $=\frac{j}{c}$ é chamada de taxa de juros e ela será sempre referida ao período da operação, ver [18]. O juro pode ser calculado de duas formas:

\section{a) Juros simples}

No regime de juros simples, a taxa de juros incide somente sobre o capital inicial durante o período de tempo determinado. Pode-se calcular os juros simples utilizando a fórmula

$$
\mathrm{j}=\mathrm{c} \times \mathrm{i} \times \mathrm{t},
$$

onde j é o juro; i é a taxa; c é o capital e t é o tempo.

Substituindo j na fórmula do montante, obtemos a fórmula:

$$
\mathrm{M}=\mathrm{c}+\mathrm{j}=\mathrm{c}+(\mathrm{cit})=\mathrm{c}(1+\mathrm{it}) .
$$

O montante no regime de juros simples possui um crescimento linear em relação a variável t.

\section{b) Juros compostos}

No regime de juros compostos, a taxa de juros sempre incide sobre o montante obtido no período anterior. No regime de juros compostos de taxa i, um principal c transforma-se, em t períodos de tempo, em um montante igual a

$$
\mathrm{M}=\mathrm{c} \times(1+\mathrm{i})^{\mathrm{t}}
$$


O montante no regime de juros compostos, possui um crescimento exponencial. Como a função exponencial é a inversa da função logarítmica, ressaltamos a importância do uso de logaritmos para resolução de problemas de Matemática Financeira em que a incógnita é o período de investimento. A respeito do uso de logaritmos em problemas de Matemática Financeira indicamos a leitura do capítulo "Aplicações" de [14].

\subsection{Taxas proporcionais e equivalentes}

Taxas proporcionais. Duas taxas são chamadas de taxas proporcionais se a razão entre elas é igual à razão dos períodos aos quais se referem quando expressos na mesma unidade de tempo, ver [18, p.59]. Ao falarmos em taxas proporcionais estaremos nos referindo ao regime de juros simples.

Exemplo 1. A taxa de $15 \%$ ao mês é proporcional à taxa de $0,5 \%$ ao dia.

De fato, expressando o período de tempo ao mês para a unidade de tempo ao dia, ou seja, 1 mês $=30$ dias, temos a proporção:

$$
\frac{15 \%}{0,5 \%}=\frac{30 \text { dias }}{1 \text { dia }}
$$

Taxas equivalentes. Duas taxas são chamadas de taxas equivalentes se, quando aplicadas ao mesmo capital inicial, por um mesmo período de tempo, produzem um mesmo montante.

Exemplo 2. A taxa de $0,5 \%$ ao dia é equivalente a taxa de $16,14 \%$ ao mês.

Detalharemos esse exemplo em breve. Por ora, observe que taxas proporcionais não são taxas equivalentes. Dessa forma, para fazer a conversão, por exemplo, de uma taxa mensal para uma taxa anual, ou vice-versa, no regime de juros compostos, não basta simplesmente multiplicar ou dividir a taxa por uma constante, como se faz nos juros simples. Por exemplo, é um erro achar que juros de $0,5 \%$ ao dia, no regime de juros compostos, equivalem a juros mensais de $30 \times 0,5 \%=15 \%$ ao mês, ver [17, p.92]. Na verdade, como citamos no exemplo $2.2,0,5 \%$ ao dia equivale a juros mensais de $16,14 \%$.

Para realizar essa conversão, inicialmente, definiremos $i_{m}$ como sendo a taxa mensal e $i_{d}$ como sendo a taxa diária. Da fórmula $\mathrm{M}=\mathrm{c} \times(1+\mathrm{i})^{\mathrm{t}}$, obtemos:

$$
c \times\left(1+i_{m}\right)^{1}=c x\left(1+i_{d}\right)^{30} \text {. }
$$

Daí, $\mathrm{i}_{\mathrm{m}}=\left(1+\mathrm{i}_{\mathrm{d}}\right)^{30}-1$.

Assim, podemos usar a equação $i_{m}=\left(1+i_{d}\right)^{30}-1$ para a conversão de uma taxa diária para a taxa mensal equivalente, ou vice-versa. No exemplo 2.2 temos $i_{d}=0,5 \%$. Logo, substituindo $\mathrm{i}_{\mathrm{d}}=0,5 \%=0,005$ em $\mathrm{i}_{\mathrm{m}}=\left(1+\mathrm{i}_{\mathrm{d}}\right)^{30}-1$, obtemos

$$
\mathrm{i}_{\mathrm{m}}=(1+0,005)^{30}-1=(1,005)^{30}-1 .
$$

Lançando mão de uma calculadora científica calculamos $\mathrm{i}_{\mathrm{m}}$ :

$$
\mathrm{i}_{\mathrm{m}} \approx 1,1614-1,
$$


isto é,

$$
\mathrm{i}_{\mathrm{m}} \approx 0,1614 \text {. }
$$

Ou seja, $\mathrm{i}_{\mathrm{m}} \approx 16,14 \%$.

Temos, para facilitar a conversão de vários períodos, a seguinte relação:

$$
\left(1+i_{d}\right)^{360}=\left(1+i_{m}\right)^{12}=\left(1+i_{b}\right)^{6}=\left(1+i_{s}\right)^{2}=\left(1+i_{a}\right),
$$

onde $i_{d}, i_{m}, i_{b}, i_{s}, i_{a}$ são, respectivamente, taxas diária, mensal, bimestral, semestral e anual.

Daí, por exemplo, obtemos:
a) $i_{d}=\left(1+i_{a}\right)^{\frac{1}{360}}-1$
b) $i_{m}=\left(1+i_{a}\right)^{\frac{1}{12}}-1$
c) $i_{b}=\left(1+i_{a}\right)^{\frac{1}{6}}-1$
d) $i_{\mathrm{s}}=\left(1+\mathrm{i}_{\mathrm{a}}\right)^{\frac{1}{2}}-1$
e) $i_{d}=\left(1+i_{m}\right)^{\frac{1}{30}}-1$
f) $i_{m}=\left(1+i_{d}\right)^{30}-1$.

Podemos dizer que no regime de juros simples, a classificação de duas taxas de juros como proporcionais ou equivalentes não fará diferença no resultado final. Isso, porém, não ocorre no regime de juros compostos, como vimos no exemplo anterior.

\section{Agradecimentos}

Este artigo é parte do meu Trabalho de Conclusão de Curso (TCC) do Profmat-Ufal. Agradeço ao Prof. Hilário Alencar pela sua orientação. Também sou grato à Larissa Cândido e à Milena Farias pelos comentários e sugestões.

\section{Referências}

[1] BANCO CENTRAL DO BRASIL. Atas do Comitê de Política Monetária (Copom): 232 ${ }^{\mathrm{a}}$ Reunião. Disponível em: <https://www.bcb.gov.br/publicacoes/atascopom/05082020>. Acesso em: 26 out. 2020.

[2] BANCO CENTRAL DO BRASIL. Calculadora do cidadão. Disponível em: <https://www3. bcb.gov.br/CALCIDADAO/jsp/index.jsp>. Acesso em: 01 out. 2020.

[3] BANCO CENTRAL DO BRASIL. Comitê de Política Monetária (Copom). Disponível em: <https://www.bcb.gov.br/controleinflacao/copom>. Acesso em: 26 out. 2020.

[4] BANCO CENTRAL DO BRASIL. Histórico das taxas de juros. Disponível em: <https:// www.bcb.gov.br/controleinflacao/historicotaxasjuros>. Acesso em: 03 nov. 2020.

[5] BANCO CENTRAL DO BRASIL. Metas para a inflação. Disponível em: <https://www.bcb. gov.br/controleinflacao/metainflacao>. Acesso em: 27 out. 2020.

[6] BANCO CENTRAL DO BRASIL. O que é inflação. Disponível em: <https://www.bcb.gov. br/controleinflacao/oqueinflacao>. Acesso em: 26 out. 2020.

[7] BANCO CENTRAL DO BRASIL. Remuneração dos Depósitos de Poupança. Disponível em: <https://www4.bcb.gov.br/pec/poupanca/poupanca.asp?frame=1>. Acesso em: 26 out. 2020 . 
[8] BRASIL. Instituto Brasileiro de Geografia e Estatística (IBGE). Inflação. Disponível em: <https://www.ibge.gov.br/explica/inflacao.php\#: :text=0\%20governo $\% 20$ federal $\%$ 20usa\%20,altera\%C3\%B5es\%20na\%20taxa\%20de\%20juros.>. Acesso em: 27 out. 2020.

[9] BRASIL. Ministério da Educação. Base Nacional Comum Curricular (BNCC). 2018, 600p. Disponível em: <http://basenacionalcomum.mec.gov.br/images/BNCC_EI_EF_110518 versaofinal_site.pdf>. Acesso em: 20 out. 2020.

[10] BRASIL. Ministério da Educação. Conselho Nacional de Educação. Resolução $n^{\circ} 4$, de 17 de dezembro de 2018. Disponível em: <https://www.in.gov.br/web/dou/-/ resolucao-n-4-de-17-de-dezembro-de-2018-55640090>. Acesso em: 25 out. 2020.

[11] BTG PACTUAL. Letra de Crédito de Agronegócio. Disponível em: <https://www. btgpactualdigital.com/renda-fixa/lca>. Acesso em: 29 out. 2020.

[12] BTG PACTUAL. Letra de Crédito Imobiliário. Disponível em: <https://www. btgpactualdigital.com/renda-fixa/lci>. Acesso em: 29 out. 2020.

[13] FARIAS, M.; CÂNDIDO, L. Uso de materiais didático-pedagógicos lúdicos por egressos do Profmat e sua influência no aprendizado em Matemática em Alagoas. Revista de Ensino de Ciências e Matemática, v. 10, nº6, pp.340-359, 2019.

[14] LIMA, E. L. Logaritmos. $2^{\text {a }}$ ed. Rio de Janeiro: Sociedade Brasileira de Matemática, 1996.

[15] MATHIAS, C. V.; ALENCAR, H.; LEIVAS, J. C. P. Provas sem palavras, visualização, animação e GeoGebra. Revista do Instituto Geogebra Internacional de São Paulo, v. 8, n²2, pp.62-77, 2019.

[16] MendeS, C. M.; TREDEZINI, C. A. de O.; BORGES, F. T. de M.; FAGUNDES, M. B. B. Introdução à Economia. $3^{\mathrm{a}}$ ed. Florianópolis: Departamento de Ciências da Administração/UFSC, 2015.

[17] MOrGado, A. C.; CARvalho, P. C. P. Matemática Discreta. $2^{\mathrm{a}}$ ed. Rio de Janeiro: Sociedade Brasileira de Matemática, 2015.

[18] MORGADO, A. C.; WAGNER, E.; ZANI, S.C. Progressões e Matemática Financeira. $6^{\mathrm{a}}$ ed. Rio de Janeiro: Sociedade Brasileira de Matemática, 2015.

[19] NETO, A. Matemática Financeira e suas Aplicações. 12. ${ }^{a}$ ed. São Paulo: Atlas, 2012.

[20] PORTAL DO INVESTIDOR. CDB (Certificado de Depósito Bancário) e RDB (Recibo de Depósito Bancário). Disponível em: <https://www.investidor.gov.br/menu/Menu_Investidor/ Old/Valores_Mobiliarios/CDB_RDB.html>. Acesso em: 29 out. 2020.

[21] PORTAL DO INVESTIDOR. Títulos Públicos. Disponível em: <https://www.investidor. gov.br/menu/primeiros_passos/Investindo/Tipos_Investimento/Titulos_publicos.html>. Acesso em: 20 out. 2020.

[22] RODRIGUES, G. F.; OLIVEIRA, E. D. de. O uso do GeoGebra no ensino de elipse nas aulas de matemática da Educação Básica. Revista Professor de Matemática Online, v. 5, n¹, pp.11-30, 2017.

[23] TESOURO DIRETO. Bancos e corretoras habilitados. Disponível em: <https://www. tesourodireto.com.br/conheca/bancos-e-corretoras.htm>. Acesso em: 28 out. 2020.

[24] TESOURO DIRETO. Calculadora. Disponível em: <https://www.tesourodireto.com.br/ titulos/calculadora.htm>. Acesso em: 28 set. 2020. 
[25] TESOURO DIRETO. Conceitos básicos sobre impostos e taxas. Disponível em: <https:// www.tesourodireto.com.br/videos/impostos-e-taxas-tesouro-direto.htm>. Acesso em: 28 out. 2020.

[26] TESOURO DIRETO. Confira a rentabilidade de cada título. Disponível em: <https://www. tesourodireto.com.br/titulos/precos-e-taxas.htm>. Acesso em: 28 set. 2020.

[27] TESOURO DIRETO. Conheça o tesouro direto: tudo o que você precisa saber sobre o tesouro. Disponível em: <https://www.tesourodireto.com.br/conheca/ conheca-o-tesouro-direto.htm>. Acesso em: 20 out. 2020.

[28] TESOURO DIRETO. Conheça o Tesouro Nacional e os seus objetivos. Disponível em: <https: //www.tesourodireto.com.br/conheca/institucional.htm>. Acesso em: 31 out. 2020.

[29] TESOURO DIRETO. Entenda a tabela de preços e taxas. Disponível em: <https: //www.tesourodireto.com.br/data/files/D4/02/8D/39/875FB610FAC28EB6018E28A8/

Entenda_tabela.pdf>. Acesso em: 09 nov. 2020.

[30] TESOURO DIRETO. Módulo 3: Curso avançado do Tesouro Direto. Disponível em: <https: //www.tesourodireto.com.br/data/files/18/A1/2B/35/855FB610FAC28EB6018E28A8/ Modulo\%203_TesouroDireto\%20_2017_.pdf>. Acesso em: 10 nov. 2020.

[31] TESOURO DIRETO. Saiba as regras do investimento. Disponível em: <https://www. tesourodireto.com.br/conheca/>. Acesso em: 20 out. 2020.

[32] TESOURO DIRETO. Site oficial do tesouro direto. Disponível em: <https://www. tesourodireto.com.br>. Acesso em: 28 set. 2020.

Luiz Eduardo da Silva Gomes

Escola Estadual Onélia Campelo 57075-655, Maceió, Alagoas, Brasil

<luiz.edu.work@gmail.com>

Recebido: 03/11/2020

Publicado: 23/12/2020 